\title{
RETRACTED ARTICLE: Going in Through the Back Door: Challenging Straight Male Homohysteria, Transhysteria, and Transphobia Through Receptive Penetrative Sex Toy Use
}

\section{Smith ${ }^{1}$}

Published online: 16 June 2018

(c) Springer Science+Business Media, LLC, part of Springer Nature 2018

The Editor-in-Chief has retracted this article as it has come to light that it does not present genuine research. This article was not authored by M. Smith as stated on submission, but Peter Boghossian, Helen Pluckrose and James Lindsay have publicly admitted it was written by them under false pretense.

The online version of this article contains the full text of the retracted article as electronic supplementary material.

Electronic supplementary material The online version of this article (https://doi.org/10.1007/s1211 9-018-9536-0) contains supplementary material, which is available to authorized users.

\section{Smith}

MsmithPURI@gmail.com

1 Portland Ungendering Research Initiative (PURI), Portland, OR, USA 